\title{
Molecular Transformation of Crude Oil in Confined Pyrolysis System and Its Impact on Migration and Maturity Geochemical Parameters
}

Yahe Zhang ${ }^{\dagger, \ddagger}$, Yuhong Liao ${ }^{\S *}$, Shaohui Guo ${ }^{\ddagger}$, Chunming $\mathrm{Xu}^{\dagger}$, and Quan $\mathrm{Shi}^{\dagger *}$

${ }^{\dagger}$ State Key Laboratory of Heavy Oil Processing, China University of Petroleum, Beijing 102249, China

${ }^{\ddagger}$ College of Science, China University of Petroleum, Beijing 102249, China

${ }^{\S}$ State Key Laboratory of Organic Geochemistry, Guangzhou Institute of Geochemistry, Chinese Academy of Sciences, Guangzhou 510640, China
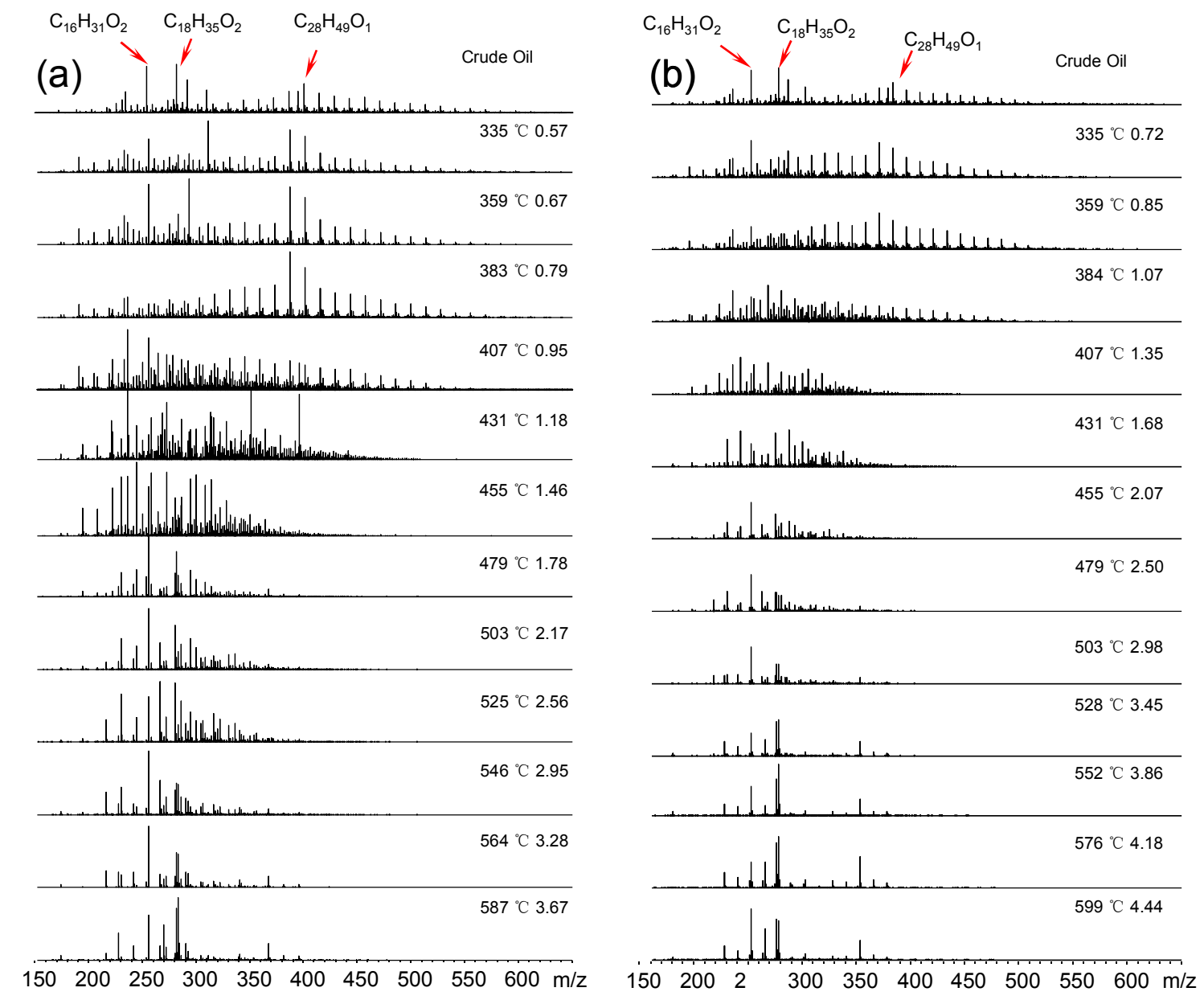

Figure S1. Negative-ion ESI FT-ICR MS broadband (150-650 Da) mass spectra of the crude oil and its pyrolysis products: (a) at $20^{\circ} \mathrm{C} / \mathrm{h}$; (b) at $2{ }^{\circ} \mathrm{C} / \mathrm{h}$. 

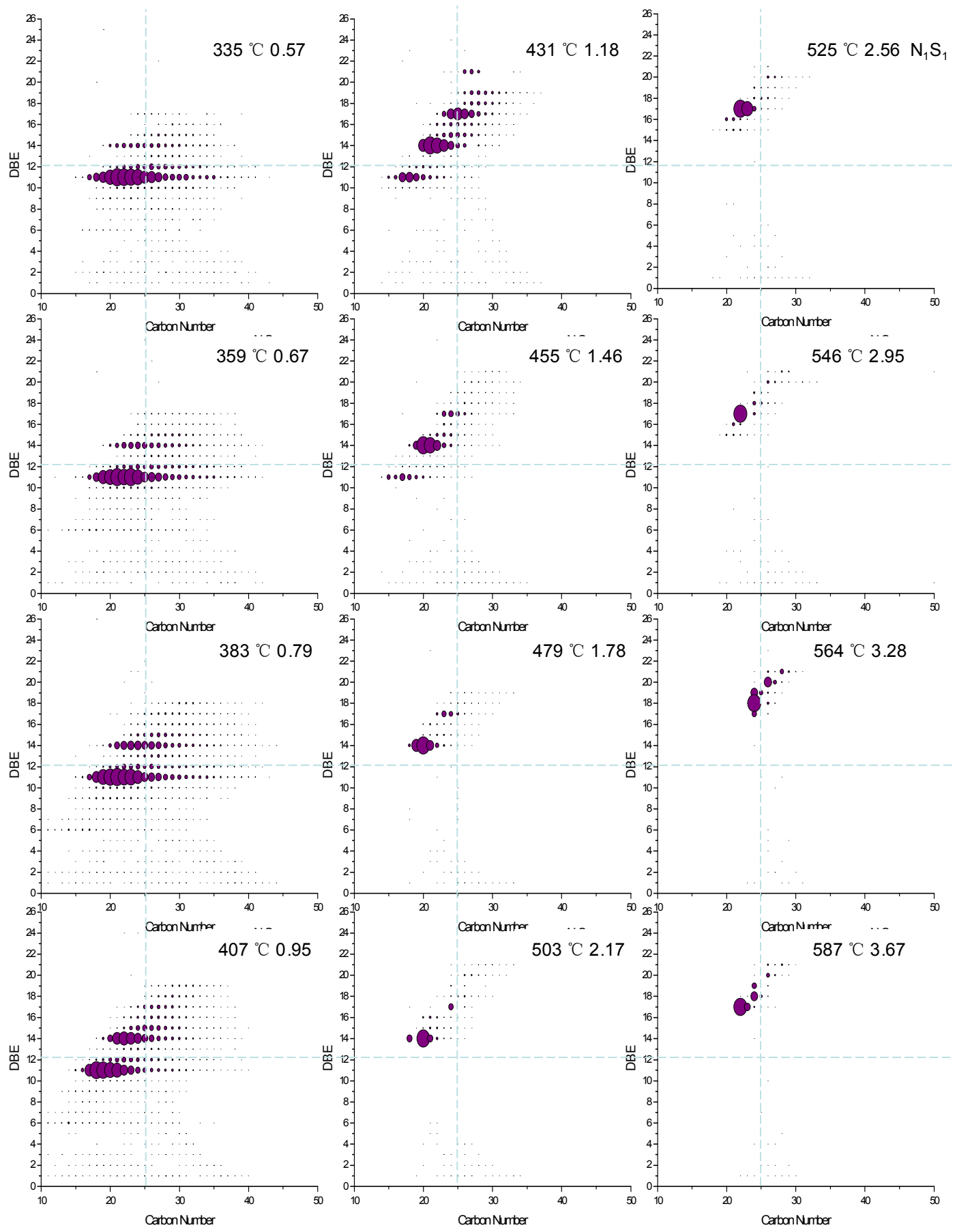

Figure S2. Plots of DBE as a function of carbon number for $\mathrm{N}_{1} \mathrm{~S}_{1}$ species in pyrolysis products from crude oil at pyrolysis heating rates of $20^{\circ} \mathrm{C} / \mathrm{h}$. 

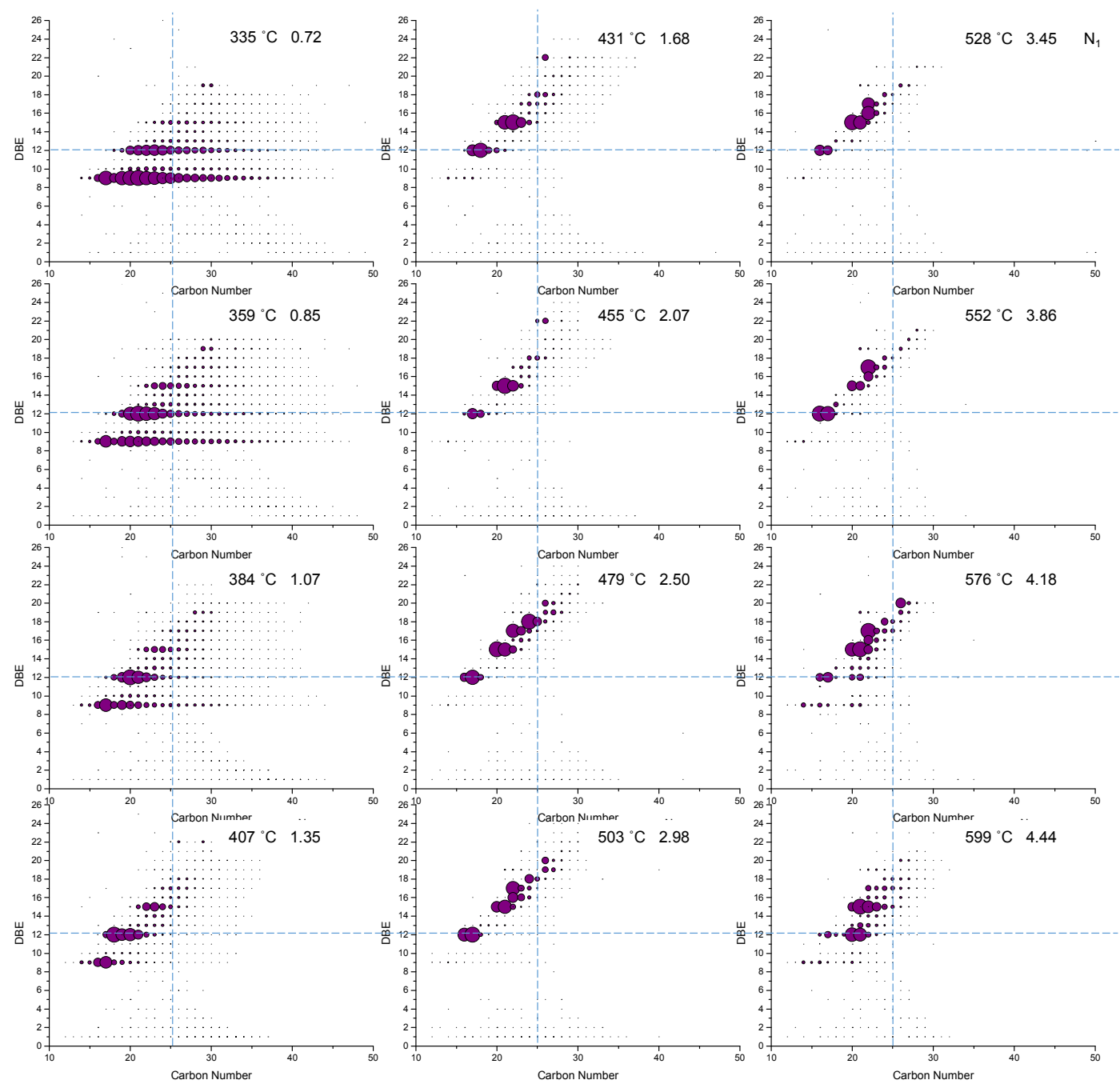

Figure S3. Plots of DBE as a function of carbon number for $\mathrm{N}_{1}$ species in pyrolysis products from crude oil at pyrolysis heating rates of $2{ }^{\circ} \mathrm{C} / \mathrm{h}$. 


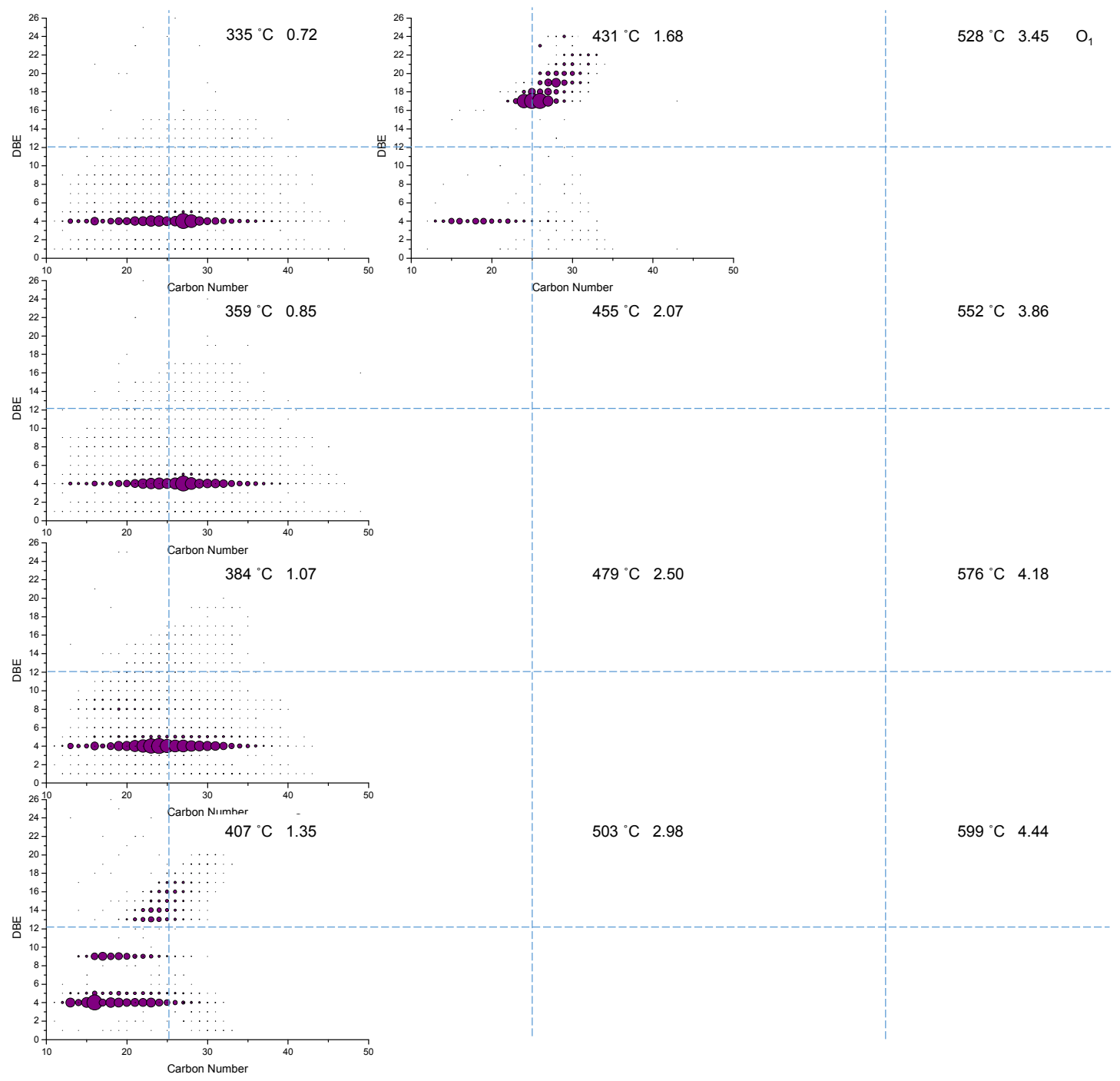

Figure S4. Plots of DBE as a function of carbon number for $\mathrm{O}_{1}$ species in pyrolysis products from crude oil at pyrolysis heating rates of $2^{\circ} \mathrm{C} / \mathrm{h}$. 

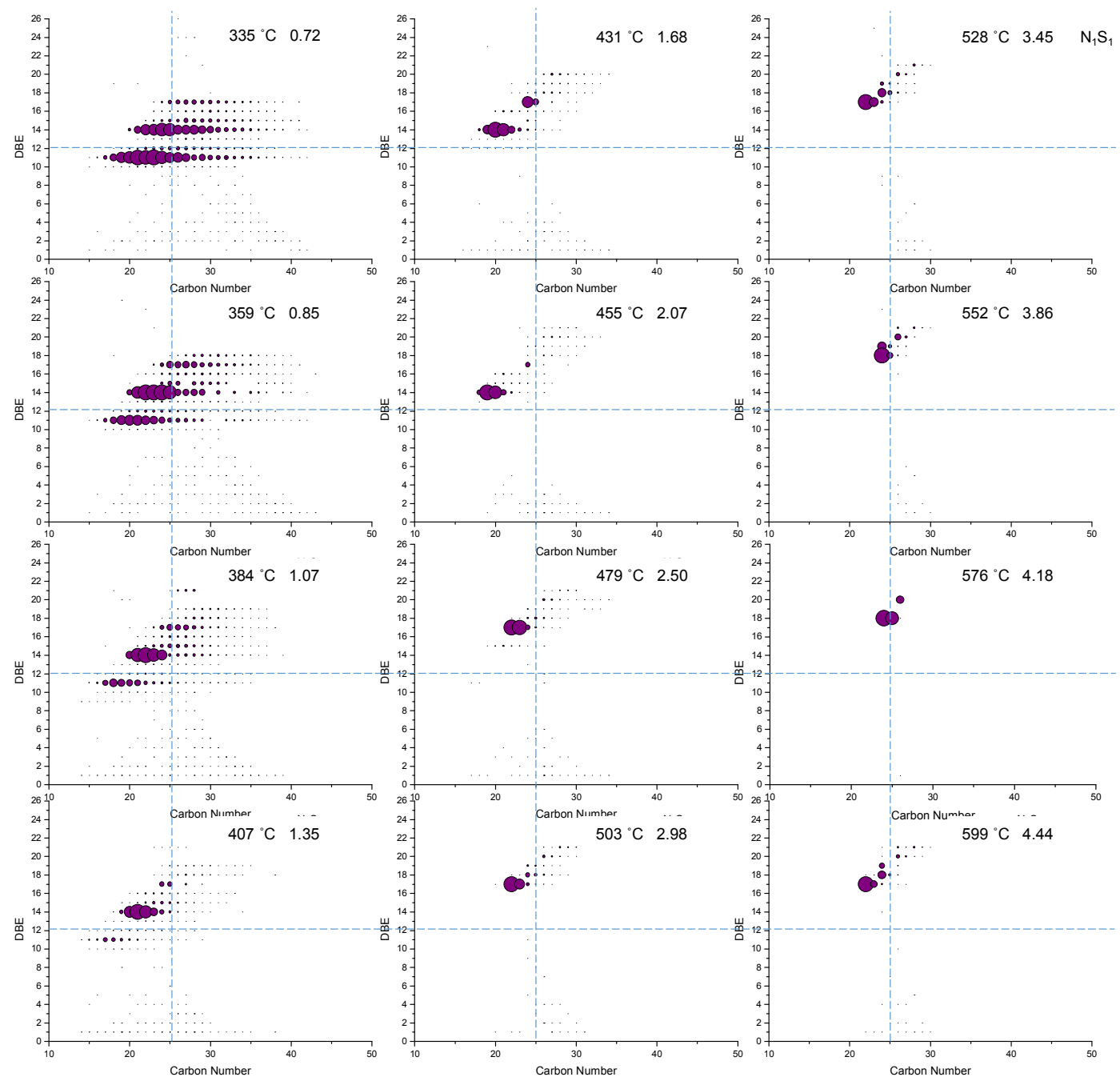

Figure S5. Plots of DBE as a function of carbon number for $\mathrm{N}_{1} \mathrm{~S}_{1}$ species in pyrolysis products from crude oil at pyrolysis heating rates of $2^{\circ} \mathrm{C} / \mathrm{h}$. 